\title{
Extraction of chitosan and its oligomers from shrimp shell waste, their characterization and antimicrobial effect
}

\author{
Tarun Kumar Varun ${ }^{1}$, Swaraj Senani², Natasha Jayapal2 ${ }^{2}$ Jayaram Chikkerur², Sohini Roy², Vijay Bhasker Tekulapally³, \\ Mayank Gautam ${ }^{1}$, and Narender Kumar ${ }^{3}$
}

1. Department of Animal Nutrition, ICAR-National Dairy Research Institute, Karnal, Haryana, India; 2. Department of Animal Nutrition, ICAR-National Institute of Animal Nutrition and Physiology, Adugodi, Bengaluru, Karnataka, India; 3. ICAR-Indian Veterinary Research Institute, Izatnagar, Bareilly, Uttar Pradesh, India.

Corresponding author: Tarun Kumar Varun, e-mail: dr.tkvarun@gmail.com,

SS: ssenani@rediffmail.com, NJ: coolnuts21@gmail.com; JC: ram.c.c80@gmail.com; SR: always.sohini@gmail.com; VBT: tvbs87.vety@gmail.com; MG: gautammayank2612@gmail.com; NK: nklangyan@gmail.com

Received: 21-07-2016, Accepted: 31-12-2016, Published online: 12-02-2017

doi: 10.14202/vetworld.2017.170-175 How to cite this article: Varun TK, Senani S, Jayapal N, Chikkerur J, Roy S, Tekulapally VB, Gautam M, Kumar N (2017) Extraction of chitosan and its oligomers from shrimp shell waste, their characterization and antimicrobial effect, Veterinary World, 10(2): 170-175.

\begin{abstract}
Aim: The present study was performed to utilize the shrimp shell waste for chitin and chitosan production, characterization by Fourier transform infrared (FT-IR) technique and to evaluate the antimicrobial effects of chitosan oligomers produced by depolymerization of chitosan by nitrous acid.

Materials and Methods: Chitosan was extracted from the shrimp shell waste by the chemical method and characterized by FT-IR. Chitooligomers were produced by depolymerising chitosan using nitrous acid, and the chitooligomers were tested for antimicrobial effect against four gut pathogenic organisms, i.e., Enterobacter aerogen (National Collection of Dairy Culture [NCDC] 106), Enterococcus faecalis (NCDC 119), Escherichia coli (NCDC 134), and Staphylococcus aureus (NCDC 109) by well diffusion method using Muller-Hinton agar. A pure culture of pathogenic organisms was collected from NCDC, ICAR-National Dairy Research Institute, Karnal.

Results: Extracted chitosan characterized by FT-IR and chitooligomers demonstrated antimicrobial effect against four gut pathogenic organisms used in this study. Zone of inhibitions (mm) were observed in E. faecalis $(13 \pm 0.20)$, E. coli

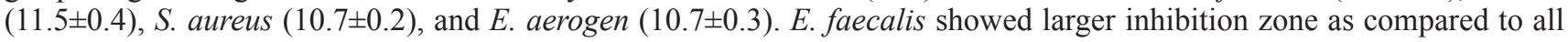
other organisms and inhibitions zones of E. aerogen and $S$. aureus were comparable to each other.
\end{abstract}

Conclusion: Shrimp waste can be utilized for chitosan production, and the chitooligomers can be used as feed additive for gut health enhancement and have potential to replace antibiotics from the feed. Along with value addition pollutant load could be reduced by waste utilization.

Keywords: chitin, chitooligomers, chitosan, Fourier transform infrared, shrimp waste.

\section{Introduction}

India is the third largest producer of the fishery in the world and hence also produces a huge amount of fish waste. Shrimp production of India was 2.7 lakh MT (Table-1). Major groups in crustaceans landings were non-peneid shrimps $(67.50 \%)$ followed by peneid shrimps $(24.35 \%)$ [1]. Chitin is the second most abundant biopolymer after cellulose in nature. Estimated annual production of chitin by living organisms is $10^{11}$ [2]. Structurally, chitin has acetamide group (-NHCOCH$)_{3}$ at $\mathrm{C}-2$ position, and rest is similar to cellulose. Chitin is a natural polymer having monomeric unit of $\mathrm{N}$-acetylglucosamine linked by $\beta, 1-4$ glycosidic linkages. Chitosan is the deacetylated product of chitin and is linear,

Copyright: Varun, et al. Open Access. This article is distributed under the terms of the Creative Commons Attribution 4.0 International License (http://creativecommons.org/licenses/by/4.0/), which permits unrestricted use, distribution, and reproduction in any medium, provided you give appropriate credit to the original author(s) and the source, provide a link to the Creative Commons license, and indicate if changes were made. The Creative Commons Public Domain Dedication waiver (http://creativecommons.org/ publicdomain/zero/1.0/) applies to the data made available in this article, unless otherwise stated. polycationic and heteropolysaccharide mainly composed of $\beta$-1,4-2-deoxy-2-amino-D-glucopyranose and $\beta$-1,4-2-deoxy-2-acetaamido-D-glucopyranose glycosidic linkages [3]. If the content of N-acetylD-glucosamine in polymer is higher than the biopolymer is chitin and if the content of glucosamine is higher than the biopolymer is chitosan [4]. Major reactive functional groups are amino/acetamide group and primary and secondary hydroxyl group at C-2, C-3, and C-6 positions, respectively. Due to the amino group content of chitosan structural, physicochemical and biological properties differs [5]. Degree of deacetylation of chitosan widely varies between $75 \%$ and $95 \%$ and molecular weight between 50 and $6000 \mathrm{kDa}$ [6]. Annual production potential of chitin in India from shrimp is 3560 tonnes [7]. Chitosan and its oligomers are known for its various biological properties such as antioxidant [8], anti-inflammatory [9], cholesterol lowering [10], immunity enhancing [11], antitumor [12], neuroprotective [13], antimicrobial [14], and antifungal [15] which makes chitosan and its oligomers very useful polysaccharide for human health. Chitosan is insoluble in water, 
Table-1: State wise details of shrimp production.

\begin{tabular}{lccc}
\hline State & $\mathbf{2 0 1 1 - 1 2}$ & & $\mathbf{2 0 1 2 - 1 3}$ \\
\cline { 2 - 2 } & $\begin{array}{ccc}\text { Estimated } \\
\text { production (MT) }\end{array}$ & & $\begin{array}{c}\text { Estimated } \\
\text { production (MT) }\end{array}$ \\
\hline West Bengal & 45,999 & & 52,581 \\
Odisha & 11,001 & & 14,532 \\
Andhra Pradesh & $1,26,466$ & & $1,59,083$ \\
Tamil Nadu & 14,960 & & 25,815 \\
Kerala & 8138 & & 5175 \\
Karnataka & 841 & & 664 \\
Goa & 51 & & 63 \\
Maharashtra & 2662 & & 3513 \\
Gujarat & 6065 & & 9393 \\
Total & $2,16,183$ & & $2,70,819$ \\
\hline
\end{tabular}

Source: Handbook of fisheries statistics. 2011. DAHDF, Ministry of Agriculture, Government of India, p 51

basic $\mathrm{pH}$ solutions and organic solvents which is a major limitation of chitosan. Chitosan is soluble in dilute organic acid like acetic acid, formic acid, etc., and form high viscous solution. Chitosan solubility depends on distribution of N-acetyl and free amino groups. Protonation of amino groups occurs at $\mathrm{pH}<6.0$ due to which chitosan become soluble [16] but at basic $\mathrm{pH}$ protonation does not occur and $\mathrm{pH}$ value of $\sim 6.5$ leads to solubility and insolubility transition [17]. Recent studies revealed the conversion of chitosan to oligomers as oligomers are soluble in water. Chitooligomers are the depolymerized product of chemical and enzymatic hydrolysis. Depolymerization of chitosan can be carried out by nitrous acid deamination [15], flurolysis using anhydrous hydrogen fluoride [18], and oxidative reduction reaction using hydrogen peroxide [19]. Chitosan with molecular weight $<39 \mathrm{kDa}$ and degree of polymerization $<20$ are known as chitosan oligomers or chitooligomers [20]. In depolymerization of chitosan with nitrous acid $\left(\mathrm{NaNO}_{2}+\mathrm{CH}_{3} \mathrm{COOH}\right)$, the amino group of chitosan selectively reacts with nitrosyl cation and forms a diazonium salt which after releasing nitrogen becomes unstable carbocation which further rearranges itself and leads to cleavage of $\beta, 1-4$ glycosidic linkage forming 2,5-anhydro-D-mannose and a detached polymer. This diazotization reaction continues until the sodium nitrite is completely consumed [15]. Mechanism of inhibition of microbial cells is by chitosan and its oligomers via its polycationic nature which electrostatically binds with the microbial surface and interferes with metabolism of bacteria or by blocking the transcription of RNA from DNA by adsorption on DNA after penetration to the cell. For penetration, the molecular weight of chitosan must be $<5000 \mathrm{kDa}$ [21]. Antimicrobial properties of chitosan mainly depend on molecular weight and degree of deacetylation.

In this study, utilization of shrimp shell waste was utilized for extraction of chitosan and its oligomers and effect of chitosan oligomers was observed on different pathogenic organisms.

\section{Materials and Methods}

\section{Ethical approval}

The experiment was conducted in accordance with the guidelines laid down by the Institutional Animal Ethics Committee for Animal Care and Management.

\section{Study area}

The study was conducted in Animal Nutrition Division, Feed additives and Nutraceutical Lab at ICAR-National Institute of Animal Nutrition and Physiology, Adugodi, Bangalore (Karnataka) in collaboration with ICAR-National Dairy Research Institute (NDRI), Karnal (Haryana).

\section{Bacterial strains}

All pure bacterial strains used were taken from National Collection of Dairy Culture (NCDC), NDRI, Karnal (Haryana). Pathogenic bacterial strains used were Escherichia coli (NCDC-134), Staphylococcus aureus (NCDC-109), Enterococcus faecalis (NCDC119) and Enterobacter aerogen (NCDC-106). All these bacterial strains were present in the lyophilized form in ampoules.

\section{Shrimp shell waste}

Shrimp shell waste was procured from Russell fish market, Shantinagar, Bengaluru (Karnataka). Sample was taken fresh and taken to the laboratory within $1 \mathrm{~h}$ of procurement.

\section{Extraction of chitosan and oligomers}

Shrimp shell waste was collected from the local fish market. Samples were taken and washed properly with flowing tap water to remove the soil and extraneous matter. Thoroughly cleaned sample was kept for drying at $80^{\circ} \mathrm{C}$ in hot air oven for 2-3 days. Dried sample was finely ground in a grinding machine and kept in the air tight container. Compositional analysis of sample was performed as per AOAC [22]. Minerals were analyzed by inductively coupled plasma optical emission spectrum (ICP-OES, Optima $8000 \mathrm{M} / \mathrm{s}$ Perkin Elmer, USA).

\section{Extraction of chitin and chitosan from shrimp shell waste}

For extraction of chitin, the conventional chemical method was followed. Chitin extraction was done following three major steps, i.e., demineralization, deproteination, and deacetylation. For demineralization, $10 \mathrm{~g}$ of sample was treated with $2 \mathrm{~N}$ hydrochloric acid at solid to solvent ratio of $1: 15$ for $2 \mathrm{~h}$ with constant stirring at $150 \mathrm{rpm}$ in incubator shaker at room temperature [23]. Acid was slowly added to avoid frothing due to gas formation occurring because of calcium carbonate content of shell which reacts with the acid and form carbon dioxide. After demineralization, the sample was washed with tap water till the sample reaches neutral $\mathrm{pH}$. Final wash was given with hot distilled water and sample was kept for drying at $80^{\circ} \mathrm{C}$ overnight.

For deproteination, demineralised shrimp shell powder was treated with $2 \mathrm{~N} \mathrm{NaOH}$ at solid to solvent 
ratio 1:20 for $2 \mathrm{~h}$ with constant stirring at $150 \mathrm{rpm}$ at $50^{\circ} \mathrm{C}$ in an incubator shaker [23] followed by thorough washing and drying as mentioned above. After this step, the end product was chitin. For deacetylation, chitin was treated with strong alkali, i.e., $1 \mathrm{~g}$ of chitin was added to $50 \% \mathrm{NaOH}$ for $1 \mathrm{~h}$ at $121^{\circ} \mathrm{C}, 15$ psi followed by washing till it reaches neutral $\mathrm{pH}$. After drying, the final product recovered was chitosan (Figure-1).

\section{Characterization of extracted chitin and chitosan}

Extracted chitosan was confirmed by solubility test in dilute acetic acid and characterization was done using Fourier transform infrared spectroscopy (FT-IR) in which spectra of standard chitosan and extracted chitosan were obtained and on the basis of absorption spectra of the standard chitosan the sample were analyzed and characterized.

\section{Chitosan oligomers production}

Hydrolysis of chitosan was done by nitrous acid $\left(\mathrm{NaNO}+\mathrm{CH}_{3} \mathrm{COOH}\right)$ for oligomers production. For hydrolysis, $2 \%$ chitosan solution in dilute $1 \%$ acetic acid and $0.5 \mathrm{M} \mathrm{NaNO}_{2}$ were added in 9:1 proportion and kept at room temperature in incubator shaker for overnight. pH was adjusted up to 6.0 using $10 \mathrm{~N} \mathrm{NaOH}$. Depolymerization could be predicted by decrease in the viscosity of chitosan.

\section{Antimicrobial properties of chitosan oligomers}

This property of chitosan oligomers was evaluated by well diffusion method. For the antimicrobial property, Muller-Hinton (M-H) agar was used. $\mathrm{M}-\mathrm{H}$ agar was used at $38 \mathrm{~g} / \mathrm{L}$ of media. This agar was divided into flasks for autoclave as per number of bacteria to be tested. After autoclave, agar was allowed to cool up to $40^{\circ} \mathrm{C}$ and then $1 \%$ of the cultured broth from mother culture was seeded into it and after mixing properly, it was poured into sterile Petri plates. After solidification of the agar, wells were punched by sterile borer aseptically under the laminar flow. $200 \mu \mathrm{l}$ of neutralized hydrolysate of chitosan containing oligomers filtered through $0.20 \mu \mathrm{m}$ polyvinyl

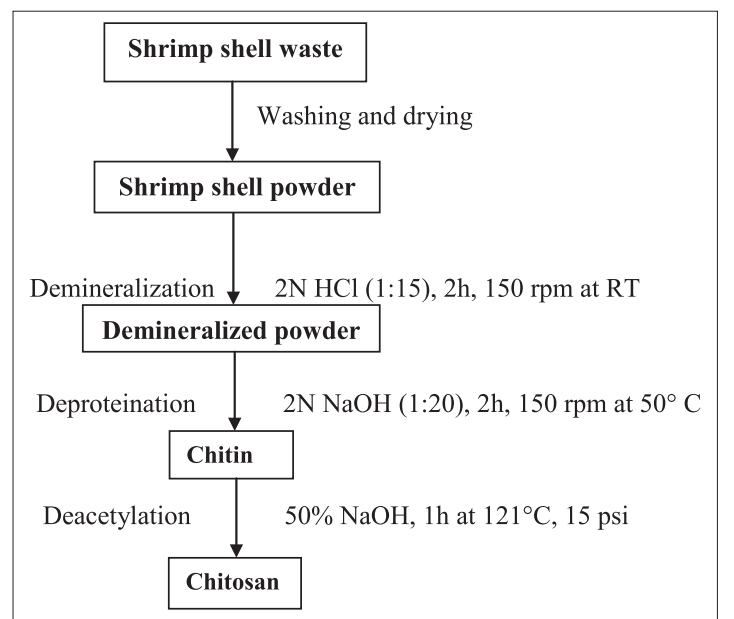

Figure-1: Flow diagram showing the steps for extraction of chitin and chitosan from shrimp shell waste. difluoride syringe filter was poured into the well. The plate was then kept in the refrigerator at $4^{\circ} \mathrm{C}$ for $1 \mathrm{~h}$ as this temperature is bacteriostatic thus during this time the oligomers can diffuse into the agar. Afterward, plates were kept at $37^{\circ} \mathrm{C}$ for $24 \mathrm{~h}$ and the diameter of zone of inhibition was measured. Blank was also prepared in the same way without chitosan. This is a preliminary study, and positive and negative control will be included in the future study. The test was done in triplicates.

\section{Results}

The shrimp shell waste contained $27.53 \pm 0.71(\%)$ dry matter (DM). Total ash, crude protein, ether extract and crude fiber (CF) (\% DM basis) were $20.02 \pm 0.09$, $50.83 \pm 0.018,4.51 \pm 0.09$ and $12.03 \pm 0.35(\%)$. Cf values showed close proximity with the amount of chitin and chitosan produced from shrimp shell waste sample. Mineral composition reveals that the amount of macro minerals, i.e., calcium, phosphorous, and magnesium (\%) were $9.08 \pm 0.32,1.37 \pm 0.05$ and $0.46 \pm 0.05$ and the amount of micro minerals, i.e., copper, zinc, iron and manganese (ppm) were 105.44 \pm 42.28 , $58.91 \pm 1.26,201.47 \pm 11.64$ and $17.91 \pm 0.68$, respectively. Yield (\%) of chitin and chitosan from the shrimp shell waste was $14.72 \pm 0.57$ and $12.03 \pm 0.46$, respectively. Formed chitosan was almost soluble in the $1 \%$ acetic acid and was characterized using FT-IR technique and com pared with the wavelength bands of the standard.

FT-IR spectrum of extracted chitosan from shrimp showed peaks at $3418 / \mathrm{cm}$ that indicated stretching vibration of - hydroxyl group, $-\mathrm{NH}_{2}$ group of amines and hydrogen bonding which was comparable to spectrum peak of standard, i.e., $3420 / \mathrm{cm} .1646 / \mathrm{cm}$ peak in extracted chitosan indicated the vibrations of carbonyl group (amide band I) and standard had this peak at $1654 / \mathrm{cm}$. Peaks at 1594/cm (extracted chitosan) and $1580 / \mathrm{cm}$ (standard) showed the presence of amide band II (N-H bendings). For - $\mathrm{CH}_{2}$ groups' in $\mathrm{CH}_{2} \mathrm{OH}$, peaks were observed at 2921 and $1422 / \mathrm{cm}$ in standard which overlapped with band spectrum at 2920 and $1421 / \mathrm{cm}$ in shrimp chitosan. $-\mathrm{CH}_{3}$ group of $\mathrm{NHCOCH}_{3}$ (amide bond) was shown at $1380 / \mathrm{cm}$ in standard and at 1381 in shrimp chitosan. Oxygen stretching of glycosidic linkage was found at $1155 / \mathrm{cm}$ in standard but in shrimp chitosan it was found at $1151 / \mathrm{cm}$. Pyranose ring was found at $895 / \mathrm{cm}$ in standard and in shrimp chitosan it was at $896 / \mathrm{cm}$. As the deacetylation process occurred, there was a variation in the intensity of carbonyl group at $1655 / \mathrm{cm}$ and amide band peak at $3449 / \mathrm{cm}$. Glycosidic linkage indicated by peak at $1151 / \mathrm{cm}$ in shrimp chitosan which overlapped with standard chitosan at $1155 / \mathrm{cm}$. The presence of $\mathrm{CH}_{3}$, $\mathrm{CH}_{2}$ and $\mathrm{CH}$ groups as well as the primary and secondary- $\mathrm{OH}$ groups which are attached to the pyranose ring, represented by the spectra between 1422 and $603 / \mathrm{cm}$ (Table-2, Figures-2 and 3). The presence of the entire band stretching in the extracted chitosan 
Table-2: Wavelength of the bands obtained by the FT-IR of extracted chitosan from Shrimp.

\begin{tabular}{lcc}
\hline $\begin{array}{l}\text { Vibration mode indicating various bonds in the } \\
\text { compound }\end{array}$ & $\begin{array}{c}\text { Std. chitosan } \\
\left(\mathbf{c m}^{-\mathbf{1}}\right)\end{array}$ & $\begin{array}{c}\text { Extracted shrimp chitosan } \\
\text { (cm }\end{array}$ \\
\hline$\left(\mathrm{NH}_{2}\right)$ assoc. in primary amines & 3420 & 3418 \\
$(\mathrm{OH})$ assoc. in pyranose ring & & 2920 \\
$\left(\mathrm{CH}_{2}\right)$ in $\mathrm{CH}_{2} \mathrm{OH}$ group & 2921 & 1646 \\
$(\mathrm{C}=\mathrm{O})$ in $\mathrm{NHCOCH}$ group (Amide I band) & 1654 & 1594 \\
$\mathrm{Amide}$ II band $(\mathrm{N}-\mathrm{H}$ bending) & 1580 & 1421 \\
$\left(\mathrm{CH}_{2}\right)$ in $\mathrm{CH}_{2} \mathrm{OH}$ group & 1422 & 1381 \\
$\left(\mathrm{CH}_{3}\right.$ in $\mathrm{NHCOCH}_{3}$ group & 1380 & 1322 \\
Amide III band (C-N stretching) & 1320 & 1151 \\
Asymmetric bridge oxygen stretching (glycosidic linkage) & 1155 & 1071 \\
$(\mathrm{C}-\mathrm{O})$ in secondary OH group & 1075 & 1020 \\
$(\mathrm{C}-\mathrm{O})$ in primary OH group & 1029 & 896 \\
Pyranose ring stretching & 895 &
\end{tabular}

FT-IR=Fourier transform infrared

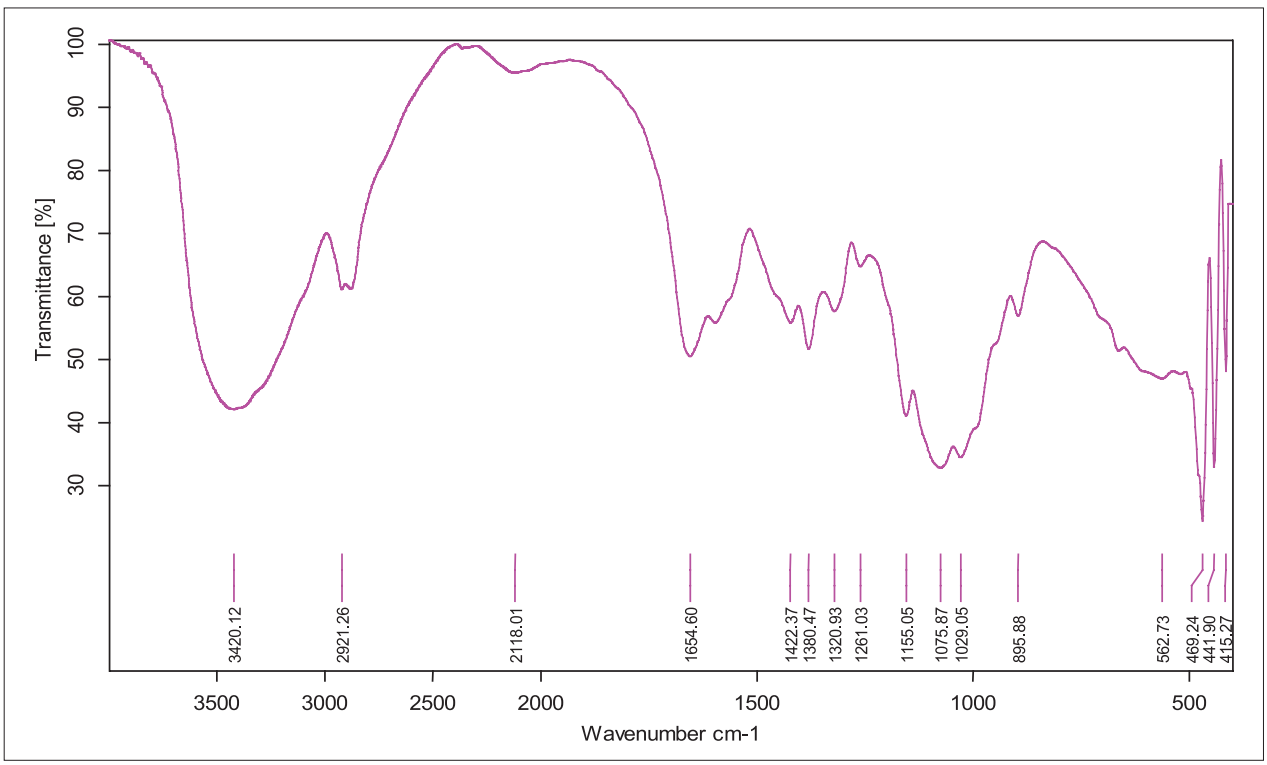

Figure-2: Fourier transform infrared of standard chitosan.

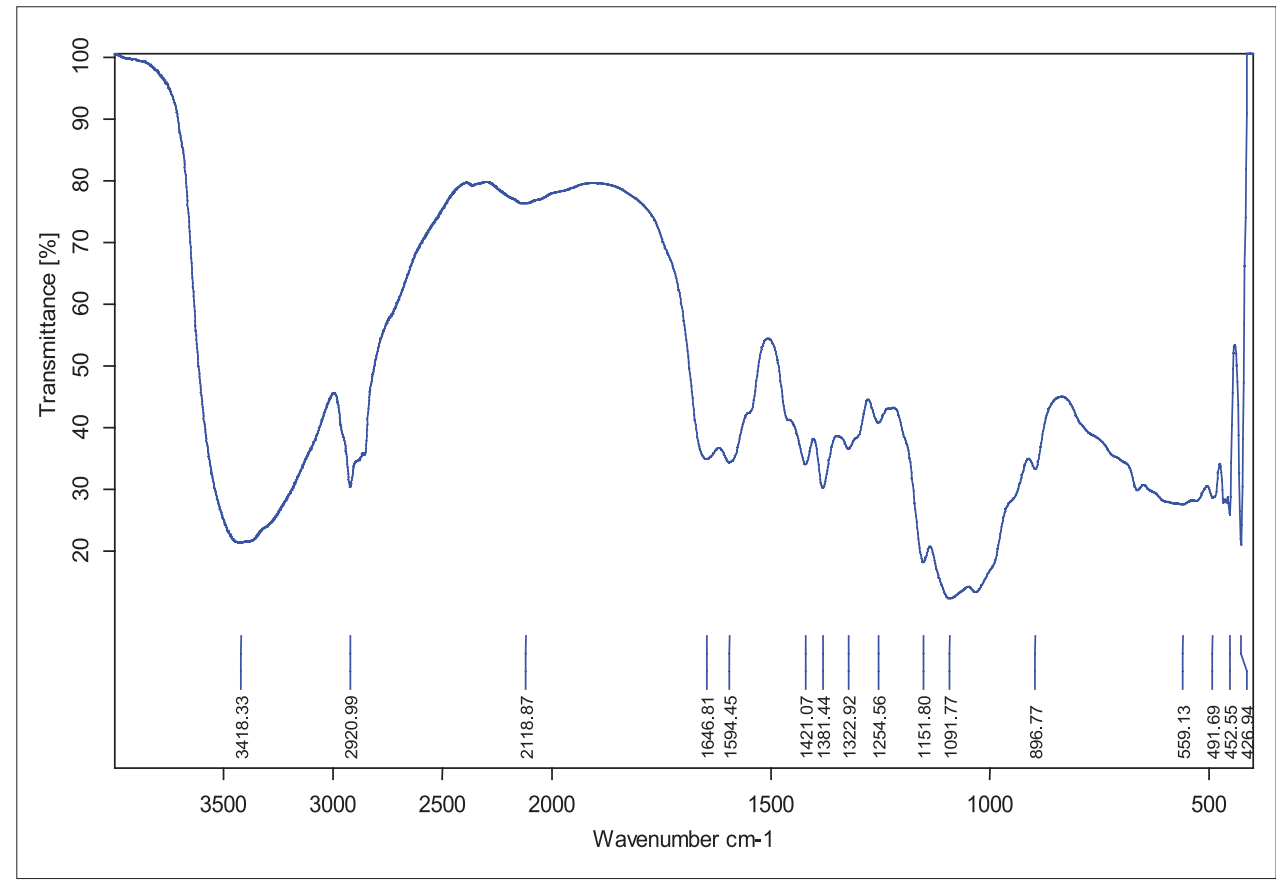

Figure-3: Fourier transform infrared of shrimp chitosan (extracted). 
compared with standard band stretching depicts that extracted material was chitosan. The FT-IR analysis confirmed that the product formed after chemical extraction was chitosan. Zones of inhibitions test were employed to study the antimicrobial effect of depolymerized chitosan oligomers. Zones of inhibitions observed for different bacterial strains under the study are shown in Table-3. This in vitro study presented the antimicrobial action of chitosan oligomers against four gut pathogenic organisms, i.e., S. aureus, E. coli, $E$. faecalis, and E. aerogen. As per reviewed literature, the antimicrobial effect is shown only if molecular weight of chitosan oligomers is $<5000 \mathrm{kDa}$, therefore, the depolymerized chitosan formed in this study should be $<5000 \mathrm{kDa}$.

\section{Discussion}

This study aimed at the utilization of shrimp shell waste for production of chitosan and its oligomers. Abdulkarim et al. [24] reported $15 \%$ yield of chitosan from shrimp shell waste which is slightly higher than yield of chitosan in study, i.e., $12.03 \%$. Recovery of chitosan in the present study from shrimp waste is $12.03 \%$ was far superior as compared to chitosan yield from shrimp shell waste reported by Isa et al. [25], i.e., $8.15 \%$. The variation could be due to difference in the age of the shrimps from which the sample was taken. FT-IR analysis of chitin and chitosan showed the band spectrums of different bonds in the present study were in close agreement with the Brugnerotto et al. [26] who observed bonds at 3436/ $\mathrm{cm}$ of hydroxyl group, 1661 and 1315/cm for amide I and amide II bonds, respectively. Zakaria et al. [27] also reported similar results; the band spectrum for hydroxyl group and $-\mathrm{NH}_{2}$ at $3438 / \mathrm{cm}$ and amide bands between 1639 and $1561 / \mathrm{cm}$ which were in close agreement with band spectrums obtained in this study.

Chitooligomers have been reported to inhibit many bacteria. Antimicrobial activity of chitosan oligomers may be due to interference in the metabolism by binding to the surface of the bacteria or by blocking of transcription of DNA and RNA by binding to the DNA after penetration into cell. Chitooligomers showed antimicrobial action against pathogenic organisms and significantly inhibited E. faecalis and the inhibitory effect on $E$. aerogen and $S$. aureus

Table-3: Inhibitory effect of chitooligomers against pathogenic organism.

\begin{tabular}{llc}
\hline S. No. & Bacteria & $\begin{array}{c}\text { Zones of } \\
\text { inhibitions } \\
\text { ( mm })\end{array}$ \\
\hline 1 & Enterobacter aerogen (NCDC 106) & $10.7 \pm 0.3^{\mathrm{b}}$ \\
2 & Enterococcus faecalis (NCDC 119) & $13 \pm 0.20^{\mathrm{a}}$ \\
3 & Escherichia coli (NCDC 134) & $11.5 \pm 0.4^{\mathrm{ab}}$ \\
4 & Staphylococcus aureus (NCDC 109) & $10.7 \pm 0.2^{\mathrm{b}}$ \\
& p value & $<0.05$ \\
\hline
\end{tabular}

Each mean value is average of four replicates. ${ }^{a}$, bMeans bearing superscript differ significantly. $\mathrm{NCDC}=$ National Collection of Dairy Culture was comparable. Chitooligomers also inhibited $E$. coli which is one of the main gut pathogenic organisms. Benhabiles et al. [23] showed antimicrobial effect of chitooligomers against many pathogenic organism, i.e., S. aureus, Salmonella typhimurium, Bacillus subtilis, Bacillus cereus, and Vibrio cholera at $0.1 \%$ concentration of chitooligomers and chitosan. Similarly, Fernandes et al. [28] showed the antibacterial effects of chitosan and chitooligomers against $S$. aureus and E. coli at $0.1 \%, 0.25 \%$ and $0.5 \%$ concentrations. Simunek et al. [29] showed the antimicrobial effect of chitooligomers on different species of Bifidobacterium. Bifidobacterium adolescentis, and Bifidobacterium longum were inhibited by the chitooligomers at concentration from $0.025 \%$ to $0.5 \%$. Shanmugama et al. [30] reported similar results about the antibacterial effect of chitosan on Gram-positive bacteria $S$. aureus and Gram-negative bacteria E. coli at various concentration of chitosan.

\section{Conclusion}

This study revealed that shrimp shell waste could be effectively utilized for the extraction of chitin, chitosan, and chitooligomers. In vitro study exhibited antimicrobial action of chitooligomers against many gut pathogens and hence could enhance the gut health. Thus, chitooligomers as feed additive could replace antibiotics in the animal feed which in turn help in dealing with problems of antibiotic residue in the animal products.

\section{Authors' Contributions}

TKV: Carried out all experimental and laboratory work. SS: Planned, guided and supervised the entire research work. NK: Helped in sample collection and its proximate analysis. NJ, SR, JC, MG helped in lab experiments and preparation of the manuscript. TVB: Carried out the data analysis. All authors have read and approved the final version of manuscript.

\section{Acknowledgments}

We are grateful to the Director, ICAR- NIANP, Bangalore and ICAR-NDRI, Karnal for providing laboratory facilities and Institutional fellowship to carry out experiment. Authors are highly thankful to staff of Animal Nutrition Division, ICAR-NIANP for providing necessary and timely help.

\section{Competing Interests}

The authors declare that they have no competing interests.

\section{References}

1. CMFRI. (2015) Annual Report 2014-15. Central Marine Fisheries Research Institute, Cochin. p353.

2. Je, J.Y. and Kim, S.K. (2006) Antimicrobial action of novel chitin derivative. Biochim. Biophys. Acta, 1760(1): 104-109.

3. Costa, E.M., Silva, S., Pina, C., Tavaria, F.K. and Pintado, M.M. (2012) Evaluation and insights into chitosan anti microbial activity against anaerobic oral pathogens. Anaerobe, 18(3): 305-309. 
4. Ramirez, M.A., Rodriguez, A.T., Alfonso, L. and Peniche, C. (2010) Chitin and its derivatives as biopolymers with potential agricultural applications. Biotechnol. Appl., 27: $270-276$.

5. Kumirska, J., Weinhold, M.X., Thöming, J. and Stepnowski, P. (2011) Biomedical activity of chitin/chitosan based materials-Influence of physicochemical properties apart from molecular weight and degree of $\mathrm{N}$-acetylation. Polymers, 3: 1875-1901.

6. Raafat, D. and Sahl, H.G. (2009) Chitosan and its antimicrobial potential - A critical literature survey. Microb. Biotechnol., 2(2): 186-201.

7. Sathiadhas, R. and Aswathy, N. (2004) Techno-economic analysis of production and marketing of marine by-products in India. J. Indian Fish. Assoc., 31: 155-165.

8. Younes, I. and Rinaudo, M. (2015) Chitin and chitosan preparation from marine sources. Structure, properties and applications. Mar. Drugs, 13(3): 1133-1174.

9. Yang, E.J., Kim, J.G., Kim, J.Y., Kim, S. and Lee, N. (2010) Anti-inflammatory effect of chitosan oligosaccharides in RAW 264.7 cells. Cent. Eur. J. Biol., 5(1): 95-102.

10. Choi, C.R., Kim, E.K., Kim, Y.S., Je, J.Y., An, S.H., Lee, J.D., Wang, J.H., Ki, S.S., Jeon, B.T., Moon, S.H. and Park, P.J. (2012) Chitooligosaccharides decreases plasma lipid levels in healthy men. Int. J. Food Sci. Nutr., 63(1): 103-106.

11. Jan, S.S., Liu, D.D., Dong, X.Y., Hu, Y.M. and Chen, J.D. (2012) Effects of chitosan and its derivative added to water on immunological enhancement and disease control. Immunotherapy, 4(7): 697-701.

12. Xu, W., Jiang, C., Kong, X., Liang, Y., Rong, M. and Liu, W. (2012) Chitooligosaccharides and N-acetyl-D-glucosamine stimulate peripheral blood mononuclear cell mediated antitumor immune responses. Mol. Med. Rep., 6(2): 385-390.

13. Pangestuti, R. and Kim, S.K. (2010) Neuroprotective properties of chitosan and its derivatives. Mar. Drugs, 8(7): 2117-2128.

14. Park, S.C., Nam, J.P., Kim, J.H., Kim, Y.M., Nah, J.W. and Jang, M.K. (2015) Antimicrobial action of water-soluble $\beta$-chitosan against clinical multi-drug resistant bacteria. Int. J. Mol. Sci., 16(4): 7995-8007.

15. Hussain, I., Singh, T. and Chittenden, C. (2012) Preparation of chitosan oligomers and characterization: Their antifungal activities and decay resistance. Holzforschung, 66(1): 119-125.

16. Padmanabhan, A. and Nair, L.S. (2016) Chitosan hydrogels for regenerative engineering. In. Dutta, P.K., editor. Chitin and Chitosan for Regenerative Medicine. Springers, New Delhi. p3-40.

17. Mano, J.F., Hugerford, G. and Ribelles, J.L.G. (2008) Bioactive poly (1-lactic acid)-chitosan hybrid scaffolds. Mater. Sci. Eng. C, 28(8): 1356-1365.
18. Defaye, J., Gadelle, A. and Pedersen, C. (1994) A convenient access to $\beta$ - $(1 \rightarrow 4)$-linked 2-amino-2-deoxy-D-glucopyranosyl fluoride oligosaccharides and $\beta-(1 \rightarrow 4)$-linked 2-amino-2-deoxy-d-glucopyranosyl oligosaccharides by fluorolysis and fluorohydrolysis of chitosan. Carbohydr. Res., 261(2): 267-277.

19. Tian, M., Chen, F., Ren, D., Yu, X., Zhang, X., Zhong, R. and Wan, C. (2010) Preparation of a series of chitooligomers and their effect on hepatocytes. Carbohydr. Polym., 79(1): 137-144.

20. Mourya, V.K., Inamdar, N.N. and Choudhari, Y.M. (2011) Chitooligosaccharides: Synthesis, characterization and applications. Polym. Sci. Ser. A, 53(7): 583-612.

21. Liu, X., Yun, L., Dong, Z., Zhi, L. and Kang, D. (2001) Antibacterial action of chitosan and carboxymethylated chitosan. J. Appl. Polym. Sci., 79(7): 1324-1335.

22. AOAC. (1990) Official Methods of Analysis. $15^{\text {th }}$ ed. Association of Official Analytical Chemists, Washington, DC, USA.

23. Benhabiles, M.S., Salah, R., Lounici, H., Drouiche, N., Goosen, M.F.A. and Mameri, N. (2012) Antibacterial activity of chitin, chitosan and its oligomers prepared from shrimp shell waste. Food hydr., 29(1): 48-56.

24. Abdulkarim, A., Isa, M.T., Abdulsalam, S., Muhammad, A.J. and Ameh, A.O. (2013) Extraction and characterisation of chitin and chitosan from mussel shell. Civ. Environ. Res., 3(2): 108-114.

25. Isa, M.T., Ameh, A.J., Gabreil, J.O. and Adama, K.K. (2012) Extraction and characterization of chitin from Nigeria sources. Leonardo Electron. J. Pract. Technol., 21: 73-81.

26. Brugnerotto, J., Lizardi, J., Goycoolea, F.M., Argüelles-Monal, W., Desbrieres, J. and Rinaudo, M. (2001) An infrared investigation in relation with chitin and chitosan characterization. Polymer, 42(8): 3569-3580.

27. Zakaria, Z., Izzah, Z., Jawaid, M. and Hassan, A. (2012) Effect of degree of deacetylation of chitosan on thermal stability and compatibility of chitosan-polyamide blend. Bioresources, 7(4): 5568-5580.

28. Fernandes, J.C., Tavaria, F.K., Soares, J.C., Ramos, O.S., Monterio, M.J., Pintado, M.E. and Malcata, F.X. (2008) Antimicrobial effects of chitosans and chitooligosaccharides, upon Staphylococcus aureus and Escherichia coli, in food model systems. Food Microbiol., 25(7): 922-928.

29. Šimůnek, J., Koppová, I., Filip, L., Tishchenko, G. and BeŁżecki, G. (2010) The antimicrobial action of low-molarmass chitosan, chitosan derivatives and chitooligosaccharides on bifidobacteria. Folia Microbiol., 55(4): 379-382.

30. Shanmugama, A., Kathiresan, K. and Nayak, L. (2016) Preparation, characterization and antibacterial activity of chitosan and phosphorylated chitosan from cuttlebone of Sepia kobiensis (Hoyle, 1885). Biotechnol. Rep., 9: 25-30. 